\title{
PREVALENCE OF HYPERTENSION AND PRE- HYPERTENSION IN 13-17 YEAR OLD ADOLESCENTS LIVING IN MTHATHA - SOUTH AFRICA: A CROSS-SECTIONAL STUDY
}

\author{
Benedicta N. Nkeh-Chungag ${ }^{1}$, Anna M. Sekokotla², Constance Sewani-Rusike ${ }^{2}$, Ambrose Namugowa², \\ Jehu E. Iputo ${ }^{2}$ \\ 'Zoology Department, Faculty of Science, Engineering and Technology, Walter Sisulu University, Mthatha, South Africa \\ ${ }^{2}$ Physiology Department, Faculty of Health Sciences, Walter Sisulu University, Mthatha, South Africa
}

\section{SUMMARY}

Background: Hypertension is one of the most common risk factors for cardiovascular diseases (CVDs), yet not much effort is being invested in early diagnosis and control of the condition in susceptible children. The aim of this study was to investigate the prevalence of pre-hypertension and hypertension in peri-urban school-attending adolescents and explore the relationship between blood pressure and selected anthropometric measurements.

Methods: A cross-sectional study of adolescents aged 13-17 years was performed. Data on height, weight, waist and hip circumferences as well as blood pressure were collected from all participants. Body mass index (BMI) and blood pressure percentiles were calculated.

Results: The overall prevalence of obesity was $20.4 \%$ while the prevalence of hypertension and pre-hypertension was $21.2 \%$ and $12.3 \%$, respectively. The prevalence of hypertension and pre-hypertension in males was $22.0 \%$ and $13.6 \%$ compared to $20.9 \%$ and $16.5 \%$ in females, respectively. Both conditions were associated with higher BMI in both girls and boys. While mean systolic blood pressure (SBP) was positively associated with higher BMl and waist circumference (WC) in males and females, it correlated negatively with hip circumference $(\mathrm{HC})$ in males. On the other hand, mean diastolic blood pressure (DBP) correlated better with $\mathrm{HC}$ in males but only weakly in females.

Conclusion: Adolescent learners in Mthatha had a high prevalence of hypertension and pre-hypertension which were associated with overweight and obesity. Results highlight the urgent need for screening in view of early detection and implementation of intervention strategies to prevent a high incidence of CVDs in this country.

Key words: adolescent, hypertension, pre-hypertension, obesity, overweight, South Africa

Address for correspondence: B. N. Nkeh-Chungag, Zoology Department, Faculty of Sciences, Engineering and Technology, PB X1, Mthatha 5117, Eastern Cape Province, South Africa. E-mail: bnkehchungag@wsu.ac.za

\section{INTRODUCTION}

Recent reports show a high prevalence of obesity in the paediatric population in both industrialized and developing countries particularly in countries undergoing a rapid epidemiological transition (1-3). Rapidly changing lifestyle and dietary patterns have led to increased prevalence of obesity in children/adolescents in developing countries. Recent reports showed the prevalence of obesity among adolescents in some developing countries to be very high: $41 \%$ in Mexico, 22\% in Brazil and India, over 19\% in Argentina, and 25\% in South Africa (4-6). According to Gupta et al. (4), important determinants of childhood and adolescent obesity include living in metropolitan cities, female gender, increased academic stress, and ready availability of fast foods. Until recently, cardiometabolic diseases were reported mostly in adults and considered to be of adult-onset. However, with the overweight and obesity epidemic also affecting children and adolescents, the incidence of these diseases has increased remarkably to the point of raising public health concern.
Several studies have reported an increased co-existence of obesity with primary hypertension, insulin resistance and hyperlipidemia in adolescents (7-9). Besides diabetes, the prevalence of high blood pressure is steadily on the rise in developing countries in both urban and rural communities (10). Importantly, research findings indicate an increase in the incidence of hypertension among children and adolescents (11-13).

The prevalence of hypertension in adolescents is generally underestimated as adult cut-off points for blood pressure instead of percentiles for height, age and sex are used. Unfortunately, the idea that hypertension is an adult-onset disease has often caused this population to be excluded from blood pressure screening exercises though elevated blood pressure in children has the same sequels as in adults and may result in target organ damage. Hypertensive children have been diagnosed with increased carotid intima-media thickness, higher prevalence of left ventricular hypertrophy and eccentric left ventricular geometry - a condition associated with increased mortality in adults (14). 
The prevalence of high blood pressure in the paediatric population of industrialized countries is between 7 and 19\% $(15,16)$. Reports from some developing countries show that over $5 \%$ of school children in India (17) have hypertension while $9.8 \%$ of primary school children in Sudan have either pre-hypertension or hypertension (18). Kemp et al. (19) reported $8.5 \%$ and $24.9 \%$ prevalence of pre-hypertension and hypertension, respectively, among South African grade 1 learners. These reports highlight the importance of investigating and addressing the causes of raised blood pressure in children for the prevention of both early and adult-onset cardiovascular diseases (CVDs).

Given the high burden of disease as well as the high patient to physician ratio in most developing countries, hypertension in children in these countries often goes undiagnosed. Another reason for the low diagnosis rate is the misconception that hypertension is only an adult-onset condition. Importantly the expression of blood pressure as percentile for height, age and sex is a time consuming procedure for the already overworked physicians in developing countries.

Having highlighted the importance of childhood blood pressure status in determining the risk of cardiovascular diseases in adult life, the aim of the current study was to determine the prevalence of hypertension and pre-hypertension in a peri-urban adolescent population living in Mthatha - South Africa and to determine whether blood pressure is associated with selected anthropometric measurements.

\section{MATERIALS AND METHODS}

A cross-sectional cohort study was conducted in high schools within $10 \mathrm{~km}$ radius of Mthatha CBD. Mthatha is a peri-urban town of the former Transkei in South Africa. It is surrounded by cattle breeding rural communities which depend on it for supplies. Participants were high school adolescents aged 13-17 years, males and females. Female participants were not pregnant nor breastfeeding. Parental consent was obtained for all participants. Ethical clearance for this study was obtained from the Walter Sisulu University Health Sciences Committee (protocol number 014/009). All measurements were performed after an overnight fast on respective school premises. All participants were requested to fill in a demographic sheet after which the following data were collected.

\section{Waist and Hip Circumference Measurement}

The WHO STEPS protocol was used to measure both waist and hip circumferences. Briefly, participants stood with arms at the side, feet positioned close together and body weight evenly distributed across both feet (20). A non-stretchable tape was placed snugly but not pulled tightly around the waist or hip. Waist circumference (WC) was measured around the smallest circumference of the waist for all participants while ensuring that the tape was horizontal across the back and front. Hip circumference (HC) on the other hand, was measured around the maximum circumference of the buttocks ensuring that the tape was horizontal across the back and front. Measurements were recorded to the nearest $\mathrm{cm}$.

\section{Height, Weight and BMI Measurements}

Height was measured in all participants without shoes to the nearest $0.1 \mathrm{~cm}$ using a stadiometer. The Omron (Body Composition Monitor BF511) designed to measure body composition in persons aged 8-80 years was used to measure weight and determine BMI. The equipment was calibrated to each participant's specific information such as height, age and sex. Obtained BMI was converted to percentiles using the Centre for Disease Control BMI percentile charts for girls and boys.

\section{Blood Pressure Measurement}

Blood pressure (BP) was measured after participants had been sitting for 5 minutes using arm circumference appropriate cuff sizes. A calibrated MicroLife automated blood pressure machine was used to measure BP once and then three times for an average value which was used for analyses. Blood pressure was measured in the right arm for all participants. Obtained BPs were converted to percentiles for height, age and sex and used for classifying participants as normotensive, pre-hypertensive or hypertensive.

\section{Data Analyses}

Descriptive statistics were computed for sex, all anthropometric measurements and BP using GraphPad Instat ${ }^{\circledR}$. Chi-squared analysis was used to test association and correlations between both systolic and diastolic BP and anthropometric data. Results were expressed as mean \pm SEM. P values $<0.05$ were considered significant. Pearson's correlation coefficients were obtained from linear regression analysis of the relationship between BP and anthropometric data.

\section{RESULTS}

\section{Characteristics of Participants}

Complete anthropometric data and BP were obtained for 388 of 392 participants. Many more females than males participated in the study. The average age for both sexes was similar though males were taller than females and females heavier than males. Females also had significantly higher BMI, WC and HC than males. Males had significantly higher waist-to-hip ratio (WHR) compared to females though females had significantly higher waist circumference-to-height ratio (WHtR) (Table 1). Mean diastolic blood pressure (MDBP) however was similar between males and females while mean systolic blood pressure (MSBP) was significantly higher only in males.

\section{Prevalence of Overweight and Obesity}

The prevalence of obesity defined as BMI percentile $>95$ th percentile for age and sex, was $10.2 \%$ and $24.8 \%$ in males and females, respectively. Separation of learners by their WHtR showed that $91.5 \%$ males compared to $51.6 \%$ females had normal healthy weight while just over $5 \%$ and $17 \%$ males and females were obese, respectively (Table 2). WHtR greatly underestimated the prevalence of obesity compared to prevalence values obtained using BMI percentiles. 
Table 1. Characteristics of participants

\begin{tabular}{|l|c|c|}
\hline & Male participants & Female participants \\
\hline No. of participants & 118 & 274 \\
\hline Age (years) & $15.0 \pm 0.1$ & $15.1 \pm 0.1$ \\
\hline Height $(\mathrm{cm})$ & $165.9 \pm 0.8$ & $159.1 \pm 0.4^{* *}$ \\
\hline Weight $(\mathrm{kg})$ & $61.4 \pm 1.4$ & $64.7 \pm 0.9^{*}$ \\
\hline BMl $\left(\mathrm{kg} . \mathrm{m}^{-2}\right)$ & $22.3 \pm 0.5$ & $25.5 \pm 0.3^{* *}$ \\
\hline Waist circumference $(\mathrm{cm})$ & $73.3 \pm 0.9$ & $78.2 \pm 0.7^{* *}$ \\
\hline Hip circumference $(\mathrm{cm})$ & $90.3 \pm 1.0$ & $100.5 \pm 0.8^{* *}$ \\
\hline WHR & $0.81 \pm 0.01$ & $0.78 \pm 0.01^{* *}$ \\
\hline WHtR $(\%)$ & $44.7 \pm 0.6^{* *}$ & $49.4 \pm 0.4$ \\
\hline MSBP $(\mathrm{mmHg})$ & $121 \pm 2$ & $118 \pm 1^{*}$ \\
\hline MDBP $(\mathrm{mmHg})$ & $72 \pm 1$ & $72 \pm 1$ \\
\hline
\end{tabular}

$\mathrm{WHR}=$ waist-to-hip ratio; $\mathrm{WHtR}=$ waist circumference-to-height ratio; $\mathrm{MSBP}=$ systolic blood pressure; MDBP= diastolic blood pressure; ${ }^{*} p<0.05 ;{ }^{* *} p<0.01$

Table 2. Prevalence of obesity using BMI and WHtR

\begin{tabular}{|c|c|c|c|}
\hline & $\begin{array}{c}\text { Whole cohort } \\
n(\%)\end{array}$ & $\begin{array}{l}\text { Males } \\
\mathrm{n}(\%)\end{array}$ & $\begin{array}{c}\text { Females } \\
\mathrm{n}(\%)\end{array}$ \\
\hline \multicolumn{4}{|l|}{ BMl } \\
\hline$>5 \mathrm{th}^{*}<85 \mathrm{th}^{*}$ & $224(57.7)$ & $88(74.6)$ & $136(49.6)$ \\
\hline$\geq 85 \mathrm{th}^{*}<95 \mathrm{th}^{*}$ & 84 (21.7) & $14(11.9)$ & $70(25.6)$ \\
\hline$\geq 95 \mathrm{th}^{*}$ & $80(20.6)$ & $12(10.5)$ & $68(24.8)$ \\
\hline \multicolumn{4}{|l|}{ WHtR } \\
\hline Lean & $249(63.7)$ & $108(91.5)$ & $141(53.6)$ \\
\hline Overweight & 95 (24.3) & $4(3.4)$ & $74(28.1)$ \\
\hline Obese & $47(12.0)$ & $6(5.1)$ & $48(18.3)$ \\
\hline
\end{tabular}

WHtR cut-off points: lean (males/female) $>0.35 \leq 0.53 />0.35 \leq 0.49$ (males/females) overweight: $>0.53 \leq 0.58 />0.49 \leq 0.54$; obese $>0.58 />0.54$; * ${ }^{*}$ percentile

\section{Prevalence of Pre-hypertension and Hypertension}

The prevalence of hypertension (SBP and DBP $\geq 95$ th percentile for height, age and sex) and pre-hypertension (SBP or DBP $>$ $90<95$ th percentile for height, age and sex or SBP/DBP $\geq 120 / 80$ $\mathrm{mmHg}$ even if percentiles are lower than 90th percentile) in the whole study cohort was $21.2 \%$ and $12.3 \%$, respectively. Hypertension and pre-hypertension were diagnosed in $22.0 \%$ and $13.6 \%$ males and in $20.9 \%$ and $11.7 \%$ females, respectively (Table 3 ).
Using BMI percentiles and WHtR to classify participants, the prevalence of hypertension and pre-hypertension was highest in overweight and obese learners. However the prevalence was higher when the WHtR was used to separate lean from overweight and obese learners compare to the classification using BMI.

\section{Effect of Selected Anthropometric Parameters on Blood Pressure}

Higher BMI, WC and WHtR conferred significantly higher $\mathrm{BP}$ in sex-specific groups. Obese and overweight males had significantly higher MSBP/MDBP compared to lean males $(125 \pm 1 / 75 \pm 1$ vs $120 \pm 1 / 71 \pm 1 ; \mathrm{p}<0.05)$. On the other hand $\mathrm{BP}$ in lean males was similar to that of overweight/obese females which was in turn higher than that of lean females. Male adolescents with WC $>75$ th percentile for age and sex had significantly higher MSBP/MDBP compared to all other groups. Waist circumferenceto-height ratios greater than $49 \%$ for females and $53 \%$ for males were associated with significantly higher BP compared to male and female learners who had lower WHtR. However, males with higher WHtR had significantly higher MSBP/MDBP compared to all other study groups (Table 4). In the female cohort, prehypertension and hypertension were associated with significantly higher BMI ( $26.3 \pm 0.6$ vs $25.1 \pm 0.4, \mathrm{p}=0.04)$ and $\mathrm{HC}(102.5 \pm 1.6$ vs $99.6 \pm 0.8, \mathrm{p}=0.05$ ) but not $\mathrm{WC}$. The prevalence of hypertension and pre-hypertension was higher in overweight and obese learners compared to lean participants. The relative risk of having pre-hypertension or hypertension associated with overweight and obesity was $1.57,95 \%$ CI $1.194-2.087, \mathrm{p}=0.0017$.

\section{Correlations between Blood Pressure and Anthropo- metric Variables}

Mean SBP correlated positively and significantly with BMI, WC and WHtR in both males and females though there was a weak negative correlation between MSBP and HC in males. On the other hand MDBP correlated only weakly with WC, HC and WHtR in both males and females (Table 5).

\section{DISCUSSION}

This cross sectional study explored the relationship between various measures of body size and BP (MSBP and MDBP) in

Table 3. Prevalence of hypertension and pre-hypertension in adolescents

\begin{tabular}{|l|c|c|c|}
\hline & Hypertension $^{* *}$ & Pre-hypertension $^{* *}$ & Normotensive $^{* *}$ \\
\hline Whole cohort $(n=391)$ & $83(21.2 \%)$ & $48(12.3 \%)$ & $260(66.5 \%)$ \\
\hline Males $(n=118)$ & $26(22.0 \%)$ & $16(13.6 \%)$ & $76(64.4 \%)$ \\
\hline Females $(n=273)$ & $57(20.9 \%)$ & $32(11.7 \%)$ & $184(67.4 \%)$ \\
\hline Lean $\left(B M I<85 t^{*}\right)(n=224)$ & $37(16.5 \%)$ & $25(11.1 \%)$ & $162(72.3 \%)$ \\
\hline Overweight $\left(B M I \geq 85 t^{*}<95\right.$ th $\left.^{*}\right)(n=84)$ & $25(29.8 \%)$ & $13(15.5 \%)$ & $46(54.7 \%)$ \\
\hline Obese $\left(B M I \geq 95 h^{*}\right)(n=78)$ & $13(16.7 \%)$ & $16(20.5 \%)$ & $49(62.8 \%)$ \\
\hline Lean $($ WhtR $>35 \leq 49 / 53 \%)(n=249)$ & $48(19.3 \%)$ & $31(12.4 \%)$ & $170(68.3 \%)$ \\
\hline Overweight $(W H t R>49 / 53 \leq 54 / 58 \%)(n=78)$ & $19(24.4 \%)$ & $6(7.7 \%)$ & $53(67.9 \%)$ \\
\hline Obese $(W H t R>54 / 58 \%)(n=64)$ & $16(25.0 \%)$ & $11(17.2 \%)$ & $37(57.8 \%)$ \\
\hline
\end{tabular}

${ }^{*}$ Percentile; **Values are: number (percentage). 
Table 4. Effects of BMI, waist circumference and waist circumference-to-height ratio on blood pressures

\begin{tabular}{|c|c|c|c|}
\hline & Anthropometric parameters and BP & Male & Female \\
\hline \multirow[t]{4}{*}{ BMI } & $\mathrm{BMI}<85 \%$ (n) & 93 & 133 \\
\hline & MSBP/MDBP & $120 \pm 1 / 71 \pm 1$ & $116 \pm 1 / 71 \pm 1$ \\
\hline & $\mathrm{BMI} \geq 85 \%(\mathrm{n})$ & 25 & 138 \\
\hline & Blood pressure & $125 \pm 1^{*} / 75 \pm 1^{*}$ & $120 \pm 1^{*} / 73 \pm 1^{*}$ \\
\hline \multirow[t]{4}{*}{ WC } & $W C<75 \%(n)$ & 90 & 199 \\
\hline & MSBP/MDBP & $119 \pm 2 / 71 \pm 2$ & $117 \pm 1 / 71 \pm 1$ \\
\hline & $W C \geq 75 \%(n)$ & 28 & 75 \\
\hline & MSBP/MDBP & $125 \pm 2^{*} / 74 \pm 2^{*}$ & $121 \pm 2^{*} / 73 \pm 1^{*}$ \\
\hline \multirow[t]{4}{*}{ WHtR } & $<49 / 53(n)$ & 108 & 142 \\
\hline & MSBP/MDBP & $120 \pm 3 / 72 \pm 1$ & $117 \pm 1 / 71 \pm 1$ \\
\hline & $\geq 49 / 53(n)$ & 11 & 130 \\
\hline & MSBP/MDBP & $127 \pm 3^{*} / 74 \pm 2^{*}$ & $120 \pm 1^{*} / 73 \pm 1^{*}$ \\
\hline
\end{tabular}

WC = waist circumference; WHtR cut-off points are $49 \%$ for males and $53 \%$ for females; MSBP = mean systolic blood pressure; MDBP = mean diastolic blood pressure; ${ }^{*} p<0.05$.

Table 5. Correlations between MSBP/MDBP with WC, HC and WHtR

\begin{tabular}{|c|c|c|c|c|}
\hline & & Whole group & Male & Female \\
\hline \multirow[t]{3}{*}{ MSBP/BMI } & $\mathrm{R}$ & 0.193 & 0.268 & 0.228 \\
\hline & $95 \% \mathrm{Cl}$ & $0.098-0.285$ & $0.098-0.423$ & $0.113-0.336$ \\
\hline & $p$ & 0.0001 & 0.002 & 0.0001 \\
\hline \multirow[t]{3}{*}{ MSBP/WC } & $R$ & 0.203 & 0.284 & 0.212 \\
\hline & $95 \% \mathrm{Cl}$ & $0.108-0.295$ & $0.115-0.438$ & $0.098-0.322$ \\
\hline & $p$ & 0.0001 & 0.001 & 0.0004 \\
\hline \multirow[t]{3}{*}{$\mathrm{MSBP} / \mathrm{HC}$} & $R$ & 0.194 & -0.051 & 0.215 \\
\hline & $95 \% \mathrm{Cl}$ & $0.099-0.287$ & $-0.225-0.126$ & $0.100-0.325$ \\
\hline & $p$ & 0.0001 & 0.5703 & 0.0003 \\
\hline \multirow[t]{3}{*}{ MSBP/WHtR } & $\mathrm{R}$ & 0.122 & 0.195 & 0.168 \\
\hline & $95 \% \mathrm{Cl}$ & $0.025-0.217$ & $0.021-0.358$ & $0.051-0.280$ \\
\hline & p & 0.014 & 0.029 & 0.005 \\
\hline \multirow[t]{3}{*}{ MDBP/BMI } & $\mathrm{R}$ & 0.128 & 0.194 & 0.107 \\
\hline & $95 \% \mathrm{Cl}$ & $0.030-0.222$ & $0.019-0.358$ & $-0.011-0.222$ \\
\hline & p & 0.010 & 0.030 & 0.074 \\
\hline \multirow[t]{3}{*}{ MDBP/WC } & $\mathrm{R}$ & 0.134 & 0.159 & 0.131 \\
\hline & $95 \% \mathrm{Cl}$ & $0.037-0.229$ & $-0.017-0.326$ & $0.014-0.245$ \\
\hline & $p$ & 0.007 & 0.076 & 0.029 \\
\hline \multirow[t]{3}{*}{ MDBP/HC } & $\mathrm{R}$ & 0.160 & 0.211 & 0.159 \\
\hline & $95 \% \mathrm{Cl}$ & $0.064-0.254$ & $0.037-0.373$ & $0.041-0.271$ \\
\hline & $p$ & 0.0012 & 0.0180 & 0.0082 \\
\hline \multirow[t]{3}{*}{ MDBP/WHtR } & $\mathrm{R}$ & 0.092 & 0.128 & 0.131 \\
\hline & $95 \% \mathrm{Cl}$ & $-0.005-0.188$ & $-0.049-0.297$ & $0.014-0.245$ \\
\hline & $p$ & 0.064 & 0.156 & 0.029 \\
\hline
\end{tabular}

adolescents living in a peri-urban community. In addition, we determined the prevalence of hypertension and pre-hypertension in this school-attending adolescent population. Obtained results showed differences in BP between male and female adolescents and positive correlation between BMI and WC on BP.

Even though participants were of similar age, females tended to have higher anthropometric data compared to males. In many rural African communities it is desirable for a female to be overweight or obese which is an indication of family fortune (21), consequently this cultural acceptance of bigger body size may play a role in this finding. Importantly, Pate et al. (22-23) showed that as girls progress in puberty, they tend to be less physically active and prefer indoor activities. This trend explains why girls may be physically bigger in this phase of their development compared 
to boys of similar age. Several studies on the other hand have shown a general trend towards greater BMI in all populations and across social classes $(24,25)$. South Africa, like most developing countries is undergoing a rapid transition which seems to be linked to the high prevalence of obesity and associated diseases (26). Mthatha is a peri-urban community which is undergoing rapid transformation resulting in a change in lifestyle and feeding habits. Indeed, the availability of fast foods in this town is almost equal to any city around the country. Consequently, adolescents are exposed to low nutrient energy dense foods which coupled with very few opportunities for physical activity create a favourable environment for development of obesity. Importantly, the prevalence of obesity in adolescents in Mthatha is comparable to the results of Kimani-Murage et al. (6) who showed a prevalence of $20-25 \%$ in older rural South African adolescents.

The effects of increased BMI on blood pressure were noted in both females and males indicating that beside the protective effects of estrogen in female adolescents, overweight/obesity tended to favour higher blood pressures. Our results confirm the findings of Erlingsdottir et al. (27), who showed an association between overweight/obesity and higher blood pressure. The mechanism whereby overweight/obesity may lead to higher blood pressure seems to be due to enhanced adipocyte secretion of adipokines and pro-inflammatory cytokines which may disrupt normal physiological function leading to increased blood pressure (27).

Although higher BMI has been associated with higher blood pressures, several studies are beginning to show that elevated blood pressure may correlate better with WC and WHtR (29-32). The current study showed that boys generally had lower WHtR compared to girls. Higher WHtR ratios were associated with higher MSBP and MDBP in both boys and girls though it was significant in the boys only. Indeed, Chen et al. (33) reported an association between higher WHtR ratios and higher MSBP and MDBP in 7 year old boys compared to girls. A recent report by Kruger et al. (34) showed that lower WHtR cut-off values $(<41 \%)$ are required for the prevention of the metabolic syndrome in black South African adolescents. Using this cut-off point on our data however failed to show any association of WHtR with higher blood pressures especially as only $16 \%$ of our participants were below that cut-off value. Dubey et al. (35) demonstrated the role of testosterone in higher blood pressure observed in males compared to age matched non menopausal women which may explain why in this study boys consistently had higher blood pressures than girls. Studies have shown that estrogen and estrogen receptor stimulation are protective of the cardiovascular system thus decreasing the incidence of CVDs $(36,37)$.

The current study showed a high prevalence of pre-hypertension and hypertension among adolescent girls and boys. This rise in prevalence of hypertension has been associated with increasing prevalence of overweight and obesity (38) which may have important implications for adolescent CVD health. Although the contribution of increased body fatness to hypertension is still debatable in children, hypertension in childhood or adolescence may trigger an early sequel of CVDs such as atherosclerosis, left ventricular hypertrophy and coronary heart diseases (39-41) leading chronic diseases in adulthood.

The early appearance of hypertension among adolescents in Mthatha suggests a greater susceptibility of these children to CVDs. The association of hypertension with BMI and WC in- dicates effects which may be attributable to the epidemiological transition with its inherent lifestyle changes tending to favour sedentary living and over-feeding. The prevalence of hypertension and pre-hypertension in our study was very high but comparable to results obtained by Kemp et al. (19), indicating that South African children may have a greater susceptibility to overweight/ obesity associated raised blood pressure which may persist into adulthood (42). Results from other developing countries $(43,44)$ have indicated modest increases in the prevalence of hypertension and pre-hypertension compared to the alarmingly high rates noted in the South African adolescent populations.

\section{CONCLUSION}

The present study showed a high prevalence of both pre-hypertension and hypertension in a peri-urban adolescent population which may be predictive of a high incidence of CVDs in the very near future. Urgent intervention strategies to prevent and control hypertension are therefore needed. This may include screening for susceptible adolescents and implementation of school exercise programmes and other activities with may address overweight/ obesity and consequently hypertension.

\section{Conflict of Interest}

None declared

Funding

This work was funded by the South African Medical Research Council (MRC) Capacity Building Fund, 2010.

\section{REFERENCES}

1. Rodrigues AN, Abreu GR, Resende RS, Goncalves WL, Gouvea SA. Cardiovascular risk factor investigation: a pediatric issue. Int J Gen Med. 2013;6:57-66.

2. Rossouw HA, Grant CC, Viljoen M. Overweight and obesity in children and adolescents: the South African problem. S Afr J Sci. 2012;108(5/6):31-7.

3. Toriola AL, Moselakgomo V, Shaw B, Goon DT. Overweight, obesity and underweight in rural black South African children. S Afr J Clin Nutr. 2012;25(2):57-61.

4. Gupta N, Goel K, Shah P, Misra A. Childhood obesity in developing countries: epidemiology, determinants, and prevention. Endocr Rev. 2012 Feb;33(1):48-70.

5. Bonvecchio A, Safdie M, Monterrubio EA, Gust T, Villalpando S, Rivera JA. Overweight and obesity trends in Mexican children 2 to 18 years of age from 1988 to 2006. Salud Publica Mex. 2009;51 Suppl 4:S586-94.

6. Kimani-Murage EW, Kahn K, Pettifor JM, Tollman SM, Dunger DB, Gómez-Olivé XF, et al. The prevalence of stunting, overweight and obesity, and metabolic disease risk in rural South African children. BMC Public Health. 2010 Mar 25;10:158-70.

7. Kotchen TA. Obesity-related hypertension: epidemiology, pathophysiology, and clinical management. Am J Hypertens. 2010 Nov;23(11):1170-8.

8. Kim J, Bhattacharjee R, Kheirandish-Gozal L, Khalyfa A, Sans Capdevila $\mathrm{O}$, Tauman R, et al. Insulin sensitivity, serum lipids, and systemic inflammatory markers in school-aged obese and nonobese children. Int J Pediatr. 2010;2010:846098. doi: 10.1155/2010/846098.

9. Raj M. Obesity and cardiovascular risk in children and adolescents. Indian J Endocrinol Metab. 2012 Jan;16(1):13-9.

10. Ibrahim MM, Damasceno A. Hypertension in developing countries. Lancet. 2012 Aug 11;380(9841):611-9.

11. Hansen ML, Gunn PW, Kaelber DC. Underdiagnosis of hypertension in children and adolescents. JAMA. 2007 Aug 22;298(8):874-9. 
12. Flynn JT, Falkner BE. Obesity hypertension in adolescents: epidemiology, evaluation, and management. J Clin Hypertens (Greenwich). 2011 May;13(5):323-31.

13. Thompson M, Dana T, Bougatsos C, Blazina I, Norris SL. Screening for hypertension in children and adolescents to prevent cardiovascular disease. Pediatrics. 2013 Mar;131(3):490-525.

14. Expert Panel on Integrated Guidelines for Cardiovascular Health and Risk Reduction in Children and Adolescents; National Heart, Lung, and Blood Institute. Expert panel on integrated guidelines for cardiovascular health and risk reduction in children and adolescents: summary report. Pediatrics. 2011 Dec;128 Suppl 5:S213-56.

15. Falkner B, Lurbe E, Schaefer F. High blood pressure in children: clinical and health policy implications. J Clin Hypertens (Greenwich). 2010 Apr;12(4):261-76.

16. Genovesi S, Giussani M, Pieruzzi F, Vigorita F, Arcovio C, Cavuto S, et al. Results of blood pressure screening in a population of school-aged children in the province of Milan: role of overweight. J Hypertens. 2005 Mar;23(3):493-7.

17. Genovesi S, Antolini L, Gallieni M, Aiello A, Mandal SK, Doneda A, et al. High prevalence of hypertension in normal and underweight Indian children. J Hypertens. 2011 Feb;29(2):217-21.

18. Salman Z, Kirk GD, Deboer MD. High rate of obesity-associated hypertension among primary schoolchildren in Sudan. Int J Hypertens. 2011;2011:629492. doi: 10.4061/2011/629492.

19. Kemp C, Pienaar AE, Schutte A. The prevalence of hypertension and the relationship with body composition in Grade 1 learners in the North West Province of South Africa. S Afr J Sports Med. 2011;23(4):117-22.

20. World Health Organization. WHO STEPwise approach to surveillance (STEPS). Geneva: WHO; 2008.

21. Benkeser RM, Biritwum R, Hill AG. Prevalence of overweight and obesity and perception of healthy and desirable body size in urban, Ghanaian women. Ghana Med J. 2012 Jun;46(2):66-75.

22. Pate RR, Stevens J, Webber LS, Dowda M, Murray DM, Young DR, et al. Age-related change in physical activity in adolescent girls. J Adolesc Health. 2009 Mar;44(3):275-82.

23. Pate RR, Dowda M, O'Neill JR, Ward DS. Change in physical activity participation among adolescent girls from 8th to 12th grade. J Phys Act Health. 2007 Jan;4(1):3-16.

24. Prättälä R, Sippola R, Lahti-Koski M, Laaksonen MT, Mäkinen T, Roos E. Twenty-five year trends in body mass index by education and income in Finland. BMC Public Health. 2012 Oct 31;12:936. doi: 10.1186/14712458-12-936

25. Ljungvall A, Zimmerman FJ. Bigger bodies: long-term trends and disparities in obesity and body-mass index among U.S. adults, 1960-2008. Soc Sci Med. 2012 Jul;75(1):109-19.

26. Misra A, Khurana L. Obesity and the metabolic syndrome in developing countries. J Clin Endocrinol Metab. 2008 Nov;93(11 Suppl 1):S9-30.

27. Erlingsdottir A, Indridason OS, Thorvaldsson O, Edvardsson VO. Blood pressure in children and target-organ damage later in life. Pediatr Nephrol. $2010 \mathrm{Feb} ; 25(2): 323-8$

28. Jonk AM, Houben AJ, de Jongh RT, Serné EH, Schaper NC, Stehouwer $\mathrm{CD}$. Microvascular dysfunction in obesity: a potential mechanism in the pathogenesis of obesity-associated insulin resistance and hypertension. Physiology (Bethesda). 2007 Aug;22:252-60.
29. Plachta-Danielzik S, Landsberg B, Johannsen M, Lange D, Müller MJ. Association of different obesity indices with blood pressure and blood lipids in children and adolescents. Br J Nutr. 2008 Jul;100(1):208-18.

30. Schneider HJ, Friedrich N, Klotsche J, Pieper L, Nauck M, John U, et al. The predictive value of different measures of obesity for incident cardiovascular events and mortality. J Clin Endocrinol Metab. 2010 Apr;95(4):1777-85.

31. Oboh HA, Adedeji AA. Correlation of waist-hip-ratio and waist-heightratio to cardiovascular risks factors in a Nigerian population. Nig Q J Hosp Med. 2011 Jan-Mar;21(1):16-24.

32. Liu Y, Tong G, Tong W, Lu L, Qin X. Can body mass index, waist circumference, waist-hip ratio and waist-height ratio predict the presence of multiple metabolic risk factors in Chinese subjects? BMC Public Health. 2011 Jan 13;11:35-41.

33. Chen TL, Choy CS, Chan WY, Chen CH, Liao CC. Waist-to-height ratio and elevated blood pressure among children in Taiwan. Indian Pediatr. 2012 Jun;49(6):463-6.

34. Kruger HS, Faber M, Schutte AE, Ellis SM. A proposed cutoff point of waist-to-height ratio for metabolic risk in African township adolescents. Nutrition. 2013 Mar;29(3):502-7.

35. Dubey RK, Oparil S, Imthurn B, Jackson EK. Sex hormones and hypertension. Cardiovasc Res. 2002 Feb 15;53(3):688-708.

36. Palmieri D, Perego P, Palombo D. Estrogen receptor activation protects against TNF- $\alpha$-induced endothelial dysfunction. Angiology. 2014 Jan;65(1):17-21.

37. Kolovou G, Giannakopoulou V, Vasiliadis Y, Bilianou H. Effects of estrogens on atherogenesis. Curr Vasc Pharmacol. 2011 Mar;9(2):244-57.

38. BeLue R, Okoror TA, Iwelunmor J, Taylor KD, Degboe AN, Agyemang $\mathrm{C}$, et al. An overview of cardiovascular risk factor burden in sub-Saharan African countries: a socio-cultural perspective. Global Health. $2009 \mathrm{Sep}$ 22;5:10. doi: 10.1186/1744-8603-5-10.

39. Kibar AE, Pac FA, Ballı S, Oflaz MB, Ece I, Bas VN, et al. Early subclinical left-ventricular dysfunction in obese nonhypertensive children: a tissue Doppler imaging study. Pediatr Cardiol. 2013 Aug;34(6):1482-90.

40. Luma GB, Spiotta RT. Hypertension in children and adolescents. Am Fam Physician. 2006 May 1;73(9):1558-68.

41. Sorof JM, Alexandrov AV, Cardwell G, Portman RJ. Carotid artery intimal-medial thickness and left ventricular hypertrophy in children with elevated blood pressure. Pediatrics. 2003 Jan;111(1):61-6.

42. Chen X, Wang Y. Tracking of blood pressure from childhood to adulthood: a systematic review and meta-regression analysis. Circulation. 2008 Jun 24;117(25):3171-80.

43. Ujunwa FA, Ikefuna AN, Nwokocha AR, Chinawa JM. Hypertension and prehypertension among adolescents in secondary schools in Enugu, South East Nigeria. Ital J Pediatr. 2013 Nov 2;39:70. doi: 10.1186/18247288-39-70.

44. Ellenga Mbolla BF, Okoko AR, Mabiala Babela JR, Ekouya Bowassa G, Gombet TR, Kimbally-Kaky SG, et al. Prehypertension and hypertension among schoolchildren in Brazaville, Congo. Int J Hypertens. 2014;2014:803690. doi: 10.1155/2014/803690.

Received May 6, 2013 Accepted in revised form August 25, 2014 